Twelve studies were eligible for a meta-analysis of anti-TNF effect on SF36 physical form. We observed a similar and significant improvement at 12 and 24 weeks. The effect at week 24 was 6.74 [95\% Cl: $5.34-8.13]$, with an important heterogeneity $\left(\mathrm{I}^{2}=84 \%\right.$; see figure)

Fatigue was evaluated in 3 studies. Adalimumab induced a significant improvement in FACIT score at 12 and 24 weeks in one study. Two studies using different scores (Fatigue Assessment Scale, BASDAl fatigue item) to assess certolizumab effect highlighted similar findings: an early improvement in fatigue at week 12, remaining significant and stable at week 24 .
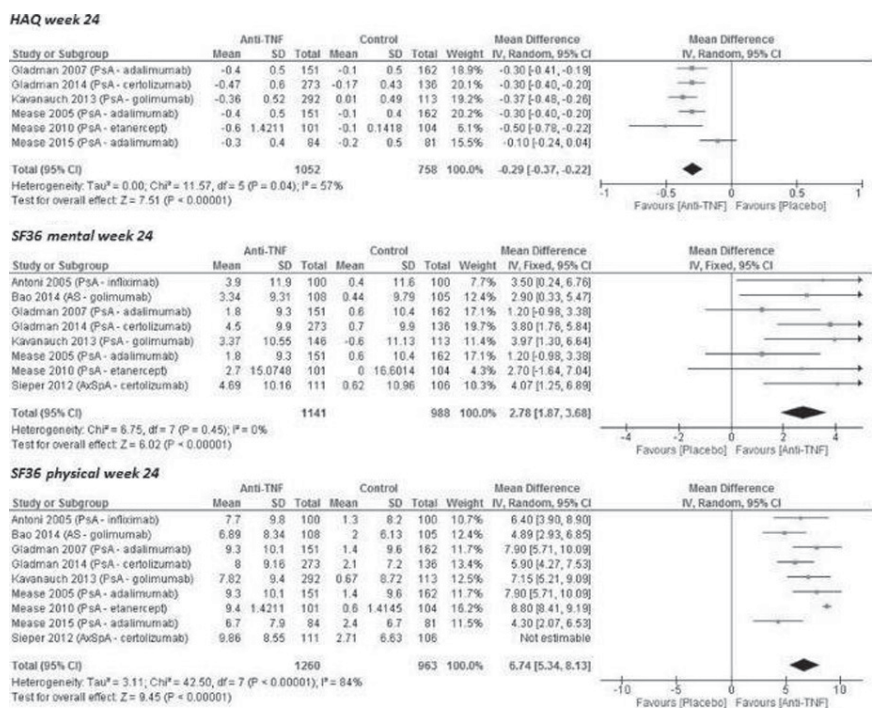

Conclusions: Anti-TNFs agents significantly improve disability, quality of life and fatigue in patients with PsA.

Acknowledgements: Abbvie France pharmaceutical company provided logistic support by organizing a meta-analysis methods workshop, but played no further role in the project.

Disclosure of Interest: None declared

DOI: 10.1136/annrheumdis-2017-eular.5268

\section{AB0704 HIP ARTHROPLASTY IN PATIENTS WITH ANKYLOSING SPONDYLITIS - CLINICAL AND FUNCTIONAL EFFICIENCY}

S. Lapshina ${ }^{1,1}$ I. Akhtyamov ${ }^{1,2}$, I. Gilmutdinov ${ }^{2}$, L. Myasoutova ${ }^{1}{ }^{1}{ }^{1}$ Kazan State Medical University; ${ }^{2}$ Republic Clinical Hospital, Kazan, Russian Federation

Objectives: To evaluate the results of the hip joints replacement in patients with $\mathrm{SpA}$ under the dynamic supervision of a rheumatologist and orthopedic within the first year after the operation.

Methods: As part of special program for rheumatology patients hip endoprosthesis was done in 12 patients (mean age - 44,2 $\pm 15,3$ years) with SpA, 8 of them with ankylosing spondylitis (AS) and 4 with psoriatic arthritis (PsA). Duration of the disease $-13,3 \pm 7,9$ years, positive for HLA B27 in $9(75 \%)$ patients. High activity for ASDAS was at $58.3 \%$ of the patients. Took NSAIDs at the time of the operation - $11(91.6 \%)$ patients, sulfasalazine $5(41.6 \%)$, methotrexate- $2(16.7 \%) .1(8.3 \%)$ patient received etanercept, $1(8.3 \%)$ patient - infliximab. Dynamic observation of rheumatologist and orthopedic was carried out before, just after surgery, after 6 and 12 months, with the assessment of VAS, BASDAI, ASDAS, BASFI.

Results: The reduction of pain intensity on the VAS was observed in the first month after the surgery $(47,3 \pm 18,6 \mathrm{~mm})$, initially it was $74,0 \pm 24,1 \mathrm{~mm}, 42.5 \pm 9$ after 6 months $(p<0.05)$, after 12 months - up to $22,5 \pm 9,9 \mathrm{~mm}(\mathrm{p}<0.05)$. ASDAS significantly $(p<0.05)$ reduced from $2,94 \pm 2,01$ to $1,68 \pm 1,35$ - in 6 months and $1,26 \pm 0,88$ - 12 months after operation; BASDAl: from $6,24 \pm 3,91$ to $2,75 \pm 2,20-6$ months, $2,65 \pm 1,53$ at 1 year follow-up. BASFI index before surgery - $5,48 \pm 3,29$, 6 months $-2,78 \pm 2,31,1$ year $-2,32 \pm 1,60$ points. No complications after surgery were registered.

Conclusions: Hip joints endoprosthesis in patients with SpA is effective not only in improving functional ability and pain relief, but also a reduction of disease activity. Dynamic rheumatologist observation in perioperative period leads to positive dynamics in relation to the activity of $\mathrm{SpA}$ and quality of life of patients during the first year after surgery

Disclosure of Interest: None declared

DOI: 10.1136/annrheumdis-2017-eular.3966

\section{AB0705 CONTINUED EFFECTIVENESS OF A BIOSIMILAR ADALIMUMAB AFTER STOPPAGE OF INITIAL TREATMENT IN PATIENTS WITH ANKYLOSING SPONDYLITIS}

S. Bandyopadhyay ${ }^{1}$, A. Ray ${ }^{2}$, R.N. Sarkar ${ }^{3}$, S. Dash ${ }^{1}$, S. Mondal ${ }^{1} .{ }^{1}$ Medicine, Apollo Gleneagles Hospital; ${ }^{2}$ Medicine, Fortis Hospital, Kolkata; ${ }^{3}$ Medicine, Calcutta Medical College, Kolkata, India

Background: Adalimumab, an anti TNF- $\alpha$ agent, has been proven to be safe and effective in treatment of ankylosing spondylitis (AS). A biosimilar adalimumab was approved for use by Indian regulators in 2014. It is a "fingerprint match" of the reference adalimumab in terms of purity, potency, safety and clinical efficacy. ${ }^{1,2}$ In the absence of availability of adalimumab in India, this biosimilar adalimumab currently serves as an accessible, cost-effective option for treatment of AS patients.

Objectives: This retrospective analysis evaluates effectiveness of biosimilar adalimumab (bADA), in terms of disease activity, safety and outcomes in real-life Indian AS patients treated for initial 24 weeks and then followed for next 24 weeks off biologic treatment.

Methods: Medical records of AS patients with Bath Ankylosing Spondylitis Disease Activity Index (BASDAI) and Bath Ankylosing Spondylitis Functional Index $(B A S F I)>4$, who were prescribed bADA therapy between January to December 2015 were analysed. For patients, who stopped bADA treatment after 24 weeks, standard AS outcome-measurement scores including ESR, CRP, BASDAI, BASFI, and Health Assessment Questionnaire (HAQ) at baseline, week 24 and at week 48 were measured to evaluate ongoing efficacy, were compared using paired Student's T-test. Patients were allowed to continue methotrexate and salazopyrin as part of routine medical care.

Results: During the study period, 52 AS patients were prescribed bADA 40 $\mathrm{mg} \mathrm{s} / \mathrm{c} ; 24$ of these patients, who had stopped treatment after 6 months, were considered for this analysis. Mean age for this group was $36.57 \pm 10.81$ years; 10 females. At the end of 24 weeks' treatment, there were significant reductions in levels of inflammatory markers ESR, CRP, as well as in BASDAI, $\mathrm{BASFI}$ and $\mathrm{HAQ}$ scores. Eight patients continued to receive methotrexate and 8 patients sulfasalazine as concomitant medications. After week 48 (24 weeks post stoppage), BASDAI and BASFI scores did not deteriorate despite discontinuation of bADA treatment. The patients' HAQ scores were also indicative of similar trends of continuing improved health status post the therapy.

Table 1. Disease activity scores and patient outcomes at 24 weeks after completion of biosimilar adalimumab therapy

\begin{tabular}{lccccc}
\hline Parameters & Baseline & $\begin{array}{c}\text { Week 24 } \\
\text { (last dose) }\end{array}$ & $\begin{array}{c}\text { P value } \\
\text { (baseline - } \\
\text { week 24) }\end{array}$ & $\begin{array}{c}\text { Week 48 } \\
\text { (24 weeks bADA } \\
\text { free period) }\end{array}$ & $\begin{array}{c}\text { P value } \\
\text { (baseline - } \\
\text { week 48) }\end{array}$ \\
\hline BASFI & $8.35 \pm 0.72$ & $2.87 \pm 0.77$ & $\mathrm{p}<0.001$ & $2.55 \pm 0.65$ & $\mathrm{p}<0.001$ \\
BASDAI & $7.70 \pm 0.84$ & $2.45 \pm 0.58$ & $\mathrm{p}<0.001$ & $2.41 \pm 0.58$ & $\mathrm{p}<0.001$ \\
ESR & $49.50 \pm 28.78$ & $13.97 \pm 11.19$ & $\mathrm{p}<0.001$ & $30.33 \pm 26.23^{\wedge}$ & $\mathrm{p}=0.02$ \\
CRP & $19.71 \pm 12.24$ & $3.58 \pm 3.6$ & $\mathrm{p}<0.001$ & $6.13 \pm 9.41$ & $\mathrm{p}<0.001$ \\
HAQ (Pain) & $67.71 \pm 7.22$ & $27.08 \pm 8.2$ & $\mathrm{p}<0.001$ & $28.13 \pm 9.42$ & $\mathrm{p}<0.001$ \\
HAQ (Health) & $60.83 \pm 8.43$ & $28.13 \pm 8.45$ & $\mathrm{p}<0.001$ & $25.63 \pm 10.56$ & $\mathrm{p}<0.001$ \\
\hline
\end{tabular}

Data presented as Mean \pm standard deviation. ${ }^{*} \mathrm{p}=$ not significant for any parameter when compared for changes from week 24 to week $48 . \wedge \mathrm{p}=0.006$ as compared to week 24 for rise in ESR during the bADA free period.

Conclusions: Biosimilar adalimumab therapy was effective in treating AS patients. The disease activity and health assessment scores continued to remain stable with no worsening after the stoppage of treatment for 6 months, indicating a post-therapy effectiveness in these patients with no reported adverse event.

\section{References:}

[1] Bandyopadhyay S, et al. Biosimilars. 2015;5:1-18.

[2] Jani RH et al. int J Rheum Dis. 2015 Jul 14.

Disclosure of Interest: None declared

DOI: 10.1136/annrheumdis-2017-eular.3825

\section{AB0706 ANKYLOSING SPONDYLITIS PATIENTS WITH UVEITIS HAD BETTER ADALIMUMAB RETENTION RATE: HUR-BIO REAL LIFE RESULTS}

B. Armagan ${ }^{1}$, A. Sari ${ }^{1}$, A. Erden ${ }^{1}$, L. Kilic ${ }^{1}$, D.C. Guven ${ }^{2}$, T. Pashayev ${ }^{2}$, E. Bilgin ${ }^{2}$, C. Simsek ${ }^{2}$, E.C. Erdat ${ }^{2}$, O. Karadag ${ }^{1}$, A. Akdogan ${ }^{1}$, S. Apras Bilgen $^{1}$, S. Kiraz ${ }^{1}$, I. Ertenli ${ }^{1}$, U. Kalyoncu ${ }^{1} .{ }^{1}$ Hacettepe University, Department of Internal Medicine, Division of Rheumatology; ${ }^{2}$ Department of Internal Medicine Hacettepe University, Ankara, Turkey

Background: Retention of biological drugs in inflammatory arthritis may be affected from different obvious and unknown factors. It can be related with patient characteritics or disease features. In ankylosing spondylitis (AS), retention rate of biological drugs may be related with extra-articular presentation of AS such as uveitis, as well.

Objectives: The objective of this study was to assess whether uveitis affected retention of adalimumab in AS patients in our single center biological cohort.

Methods: Hacettepe University Biological registry is single-center biological registry since 2005. HURBIO had 2165 spondyloarthritis patients of which 1190 patients had AS according to NY criteria. Until now, in 510 of 1190 patients have used adalimumab and 350 of 510 patients had available for uveitis. Patients 